\title{
Preparation and Characterization of Modified Reclaimed Asphalt by Using Styrene - Butyl Acrylate Nanoemulsioncopolymer
}

\author{
A.M. Nasser ${ }^{1}$, H. Abd El-Wahab ${ }^{1}$, M. Abd El-Fattah ${ }^{2}$, Abdelzaher E.A. Mostafa ${ }^{3}$ \\ and Ahmed G. Sakr ${ }^{*}$ \\ ${ }^{1}$ Chemistry Department, Faculty of Science, Al-Azhar University, Cairo, Egypt \\ ${ }^{2}$ Production Department, Egyptian Petroleum Research Institute (EPRI), Cairo, Egypt \\ ${ }^{3}$ Civil Engineer Department, Faculty of Engineering at Mataria, Helwan University, \\ Cairo, Egypt and ${ }^{4}$ Chemist, Arab Consulting Engineer office, Cairo, Egypt.
}

\begin{abstract}
$\mathbf{R}$ ECLAIMED Asphalt Pavement (RAP) is beneficial because it provides and decreases the cost of the construction, while increasing environmental sustainability. The main purpose of this study is to investigate the best practice of RAP in Egypt, in order to determine the effect of using $100 \%$ RAP instead of using virgin aggregates and asphalt. The study also investigates the effect of thermoplastic elastomers polymer as asphalt modifier. Also, improve the mechanical and physical characteristics and hence improving the quality of asphalt paving, increase asphalt-paving age and reduce the cost.
\end{abstract}

Nano acrylate copolymer has been prepared with different wt.\% and was tested for Fourier Transforms Infrared (FTIR), Molecular Weight (Mwt), Thermo Gravimetric Analysis (TGA) and Transmission Electron Microscopy (TEM). A 4wt.\% of the prepared nanoemulsion copolymer was mixed with virgin asphalt as a polymer modifier, to improve and reuse of the RAP. The modified binder was tested. The tests conducted include penetration, kinematic viscosity, softening point and specific gravity. Application of Marshall mix design types; Hot Mix Asphalt (HMA), Warm Mix Asphalt (WMA) and Cold in place Recycled (CIR). Four different mix designs were used; control mix contains virgin asphalt by HMA, where the other three mix designs were Polymer Modified Asphalt (PMA) by HMA, WMA and CIR. The research results showed that, using $4 \mathrm{wt} . \%$ of the prepared nanoemulsion copolymer producing HMA and WMA with higher stability compared to the control mix and CIR.

Keywords: Acrylate copolymer; Reclaimed Asphalt Pavement; Modified asphalt; Hot Mix Asphalt; Warm Mix Asphalt; Cold In place Recycled.

\section{Introduction}

RAP is comprised of aggregates and asphalt binder from Hot Mix Asphalt (HMA) mixtures that have been removed and reclaimed from an existing pavement. The aggregates in the RAP are coated with aged (oxidized) asphalt binder $[1,2]$. RAP has been used successfully in surface HMA mixtures since the 1970 s at percentages generally around $20 \%$. A concern associated with the use of higher RAP contents is that the resultant mixture might become too stiff and consequently might be prone to failures in the field $[3,4]$. The increased stiffness is due to the aged binder in the RAP. The major factor contributing to the increase in stiffness of asphalt concrete mixtures over time is the oxidation of the asphalt binder at the molecular level [5]. With increases in the price of asphalt cement and subsequent price fluctuations, the industry has further amplified its recycling efforts. Most recently, with the drastic increases in the cost of asphalt cement, the use of RAP has become another 'black gold' $[6,7]$. The hot mix asphalt industry is constantly seeking technological improvements to produce sustainable, cost effective, and environmentally friendly mixes [8]. A logical approach to achieve such mixtures is to use readily available recycled materials like RAP. Also, to advance environmental stewardship, the industry has been using WMA technologies that allow for the production of asphalt mixtures at temperatures in the range of $17^{\circ}$ to $54^{\circ} \mathrm{C}\left(30^{\circ}\right.$ to $100^{\circ} \mathrm{F}$ ) lower than typical hot mix asphalt [9], where Cold in-place recycling (CIR) is the processing and treatment with bituminous and/or

*Corresponding author e-mail: nilechemist201000@yahoo.com

Mobil: +201001916165, Mobil: +201001390731

DOI :10.21608/ejchem.2018.2956.1245

C2017 National Information and Documentation Center (NIDOC) 
chemical additives of existing HMA pavements without heating to produce a restored pavement layer [10]. Rejuvenating additives can be used to counteract the stiffness of the RAP binder, therefore enabling the use of RAP in HMA. It has been documented that rejuvenating agents can be carried by polymers, copolymers and terpolymers because of its absorptive properties, to revitalize the properties of the RAP binder [11]. Nanoemulsion copolymers which have very small particles and used as an asphalt modifier are introduced into asphalt mixtures through HMA, WMA or CIR. Many properties of polymers such as process ability, electrical properties, chemical, thermal, mechanical and environmental stability, affect their suitability and reliability as protective organic coatings [12]. Compatibility between polymer and asphalt should be high enough to avoid separation phase. Styrene - butyl acrylate ( $\mathrm{St}-\mathrm{BuA}$ ) is one of the copolymers which is used to improve the properties of asphalt pavements [13]. The present study is a part of a wider research on performances and durability of asphalt mixtures made with RAP [14]. The research is divided into three stages: in the first stage, the asphalt extracted from RAP and the solid materials evaluated. The second stage, preparation of St-BuA copolymer and test the physical characteristics of nanoemulsion polymer; Fourier transform infrared (FTIR), Molecular weight (Mwt), Thermo gravimetric analysis (TGA), Transmission electron microscopy (TEM) [15], then added to the virgin asphalt for improving the asphalt characteristics [16]. Application of Marshall Stability forms the last stage of the experimental.Asphalt applied as HMA, WMA \& CIR Asphalt which conforms to Marshall properties are showing high resistance to stresses caused by high loads, high working temperatures and low temperatures due to weather conditions. HMA design using virgin asphalt as a control mix and hot mixes using the virgin asphalt [17]. The effects of polymer modified asphalt of RAP with prepared nanoemulsion physical properties have been widely investigated [18]. The objective of the research is to comprehensively characterize RAP mixtures in terms of performances of asphalt mixtures and asphalts by observing Marshall characteristics out of mix designs [19].

\section{Problem statement}

Despite recent advancements in the design of asphalt mixtures containing RAP, it is still in Egypt cautious in their regulations to avoid durability problems related to the recycling process.

Egypt.J.Chem. Vol. 61, No.2 (2018)
Modifications to the current specifications are needed to assure that satisfactory performance will result from the reuse of RAP mixes.

\section{The objectives of the work}

The main objective of this study is to investigate the best practice of RAP in Egypt. Also, improving the mechanical and physical characteristics and hence improving the quality of asphalt paving, increase asphalt-paving age and reducing the cost. The other objectives of this research are set as follows:

1. Determine the effect of using $100 \%$ RAP instead of using virgin aggregates and asphalt.

2. Investigate the effect of thermoplastic elastomers nanoemulsion copolymer as asphalt modified.

3. Investigate the optimum modified asphalt content to improve the asphalt mix properties.

\section{Experimental}

\section{Materials}

St-BuA monomers, sodium lauryl ether sulfate (SLS), potassium per sulfate (KPS), Sodium acetate, and acrylamide were obtained from Sigma-Aldrich Company. Texapon $\mathrm{P}$ and nonyl phenol "NP30" were obtained from BASF. Cetyl alcohol was obtained from Dow Chemical Company. Ammonium hydroxide was produced by El-Nasr Pharmaceutical Chemical Company. The RAP used in this study, was obtained from a highway pavement in Cairo - Alexandria road, Egypt.

\section{Methods and techniques \\ Preparation of styrene-butyl acrylateco- polymer [20]}

The polymerization was carried out in $500 \mathrm{ml}$ 3-necked flask fitted with a reflux condenser, thermometer and a mechanical stirrer. The temperatures of homogenization and polymerization were $25 \& 80^{\circ} \mathrm{C}$ respectively, and nitrogen was purged during the polymerization step. Recipes for different ratios of St-BuA copolymer are presented in Table 1 and Scheme 1. During the process, the surfactant quantity was divided into two parts, namely, A \& B with the ratio of 1:3 and the process included the following steps:

1. Part A containing styrene and butyl acrylate were emulsified in a little amount of deionized water, and homogenized for 15 $20 \mathrm{~min}$ at speed $3500 \mathrm{rpm}$ in order to form pre-emulsion $\mathrm{C}$. 
2. $10 \%$ of $\mathrm{C}$ was seeded to the reactor, containing $\mathrm{B}$; de-ionized water and $\mathrm{pH}$ regulator, during $15 \mathrm{~min}$ with low speed mechanical agitator $(80 \mathrm{rpm})$ and at $80^{\circ} \mathrm{C}$. The allowed time for micelle formation was an additional $15 \mathrm{~min}$.

3. Acrylic acid and acrylamide monomers were added to the remainder of part C $(90 \%)$, under the homogenizer for 5-10 min.

4. Afterward, this acidic emulsion was added to the reactor through dropping funnel in 150 $\min$.
5. In steps $2 \& 4$, a continuous dropping of the initiator solution was performed in the reactor.

6. After adding all materials, polymerization was allowed to continue for additional 2 hrsthen the reaction mixture was cooled to $50^{\circ} \mathrm{C}$ and subsequently neutralized with aqueous ammonium hydroxide to reach a $\mathrm{pH}$ value of 8 .

TABLE 1. Recipe of styrene Bu-A nanoemulsion copolymer.

\begin{tabular}{lcc}
\hline \multicolumn{1}{c}{ Components } & Wt. \% & Wt. gm \\
\hline Styrene (ST) & 22 & 110.0 \\
Butyl acrylate BuA & 28 & 140.0 \\
Sodium lauryl ether sulfate (SLS) & 0.6 & 3 \\
EthoxylatedNonyl Phenol (NP $\left.{ }_{30}\right)$ & 2.0 & 10 \\
potassium per sulfate (KPS) & 0.75 & 3.75 \\
Sodium acetate ( $\left.\mathrm{C}_{2} \mathrm{H}_{3} \mathrm{O}_{2} \mathrm{Na}\right)$ & 0.6 & 3 \\
Acrylamide (AA) & 4 & 20 \\
Dist. $\mathrm{H}_{2} \mathrm{O}$ & 42.05 & 210.25 \\
\hline
\end{tabular}
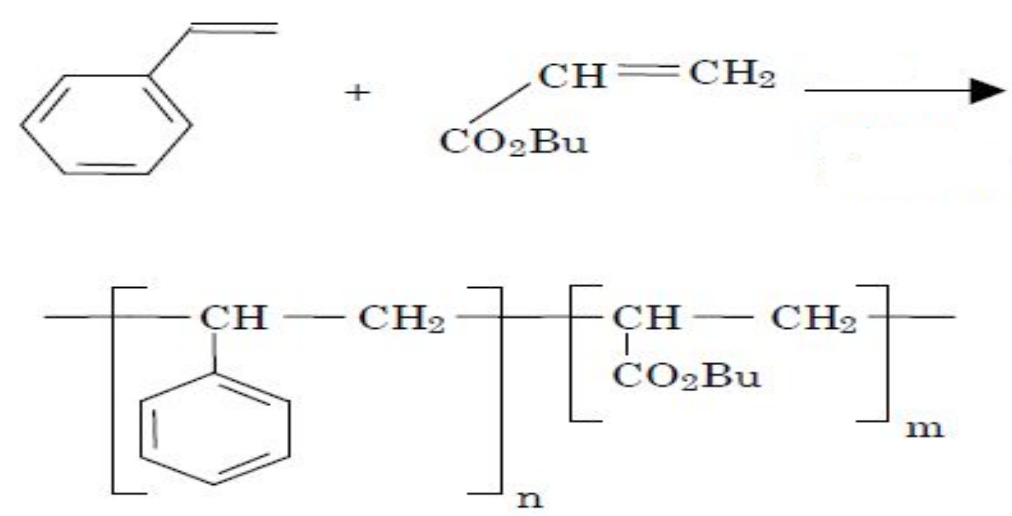

Scheme 1. Chemical structure of the prepared styrene butyl acrylate nanoemulsion copolymer.

Characteristics of styrene- butyl acrylatecopolymer

Fourier transform infrared (FTIR), Transmission electron microscopy (TEM), Thermo gravimetric analysis (TGA) and Molecular weight (Mwt) were used to characterize the prepared nanoemulsion terpolymer. These tests were carried out at the Egyptian National Research Center.

\section{A. Fourier transform infrared (FTIR)}

The copolymer composition of dried samples was proved by FTIR spectra using JASCO FTIR
6100 in the range of $4000-400 \mathrm{~cm}^{-1}$ using $\mathrm{KBr}$ pellets. FTIR was also used to examine the functional group of the prepared samples.

B. Transmission electron microscopy (TEM)

The morphology of the polymer particles was examined using transmission electron microscopy. In TEM the dry sample has to be transferred into ultra-high vacuum and is illuminated by a highenergy beam of electrons (for example100 keV). In an ideal case, a lateral resolution of around 1 $\mathrm{nm}$ is achievable. To perform TEM analysis, the latex was diluted with distilled water, a drop of the 
diluted latex was placed on a carbon - coated grid and dried in a dissector, then, $1-2$ drops of a 0.8 wt. \% aqueous solution of phosphotungstic acid (PTA) was used to stain the particles.

C. Thermo gravimetric analysis (TGA)

TGA analysis was performed using Shimadzu TGA - 50 thermo gravimetric analyzer, Columbia, EUA, in a nitrogen atmosphere at a heating rate of $10{ }^{\circ} \mathrm{C} / \mathrm{min}$ in the range between room temperature and $600{ }^{\circ} \mathrm{C}$.

\section{Molecular weight (Mwt)}

The sample $0.01 \mathrm{~g}$ was dissolved in $2 \mathrm{ml}$ of THF solvent, then was filtrated by siring filter 0.45 micro, and the sample put in gel permeation chromatography (GPC) device. Using agilent 1100 series, Germany, Detector: Refractive Index. For THF solvent (polystyrene standard) Plgel particle size $(5 \mu \mathrm{m}), 3$ columns of pore type $(100,104 \& 105$ $\mathrm{A}^{0}$ ) on series $7.5^{*} 300 \mathrm{~mm}(\mathrm{Mw} 1000,4000000)$.

\section{Preparation of the modified asphalt}

The calculated amount of virgin asphalt was heated to a temperature not more than $90^{\circ} \mathrm{C}$.
Surfactant $\mathrm{NP}_{9}$ was added 10 wt. $\%$ of the virgin asphalt, to improve the durability of the asphalt. The nanoemulsion copolymer was added slowly at $80^{\circ} \mathrm{C}-90^{\circ} \mathrm{C}$ at $2,4 \& 6$ wt. $\%$ of asphalt. St$\mathrm{BuA}$ copolymer was mixed under high-speed mixer of $2000 \mathrm{rpm}$ and stirring for $2 \mathrm{hrs}$. The virgin and polymer modified asphalt samples (PMAs) were characterized by conventional asphalt tests as penetration test (ASTMD5 - 06), softening point test (ASTMD36 - 06), specific gravity (ASTMD70 - 09), kinematic viscosity test (ASTMD2170 - 10).

Characteristics of the solid materials

The solid materials were obtained after the extraction of asphalt from RAP and tested for sieve analysis (ASTMC136-14), resistance to abrasion using Los Angeles machine (ASTMC131- 14) and bulk specific gravity (ASTMC128-15 \&12715 respectively). Tables $2-3$ show the sieve analysis and physical properties of the fine and the coarse aggregates, the obtained result was found to comply with the standard requirements.

TABLE 2. The sieve analysis for RAP according to the Egyptian Standard Specification.

\begin{tabular}{|c|c|c|c|}
\hline Sieve Size & $\begin{array}{c}\text { Gradation before } \\
\text { extraction \% Passing }\end{array}$ & $\begin{array}{c}\text { Gradation after } \\
\text { extraction \% Passing }\end{array}$ & $\begin{array}{l}\text { Limits of the binder mix } \\
\text { Egyptian Standard Specification } \\
\text { (Dense-Graded 4D),2008 }\end{array}$ \\
\hline $37.5 \mathrm{~mm}\left(1 \frac{1}{2}{ }^{\prime \prime}\right)$ & 100 & 100 & ------- \\
\hline $25.0 \mathrm{~mm}(1 ")$ & 100 & 100 & $80-100$ \\
\hline $19.1 \mathrm{~mm}(3 / 4 ")$ & 84.1 & 88.5 & $70-90$ \\
\hline $12.5 \mathrm{~mm}(1 / 2, ")$ & 76.4 & 80.3 & ------- \\
\hline $9.5 \mathrm{~mm}(3 / 8 ")$ & 68.4 & 72.1 & $55-75$ \\
\hline $4.75 \mathrm{~mm} \mathrm{\# 4}$ & 54.3 & 59.7 & $45-62$ \\
\hline $2.36 \mathrm{~mm} \mathrm{\# 8}$ & 39.2 & 43.8 & $35-50$ \\
\hline $0.6 \mathrm{~mm} \# 30$ & 19.5 & 24.6 & $19-30$ \\
\hline $0.3 \mathrm{~mm} \# 50$ & 11.4 & 14.5 & $13-23$ \\
\hline $0.15 \mathrm{~mm} \# 100$ & 2.4 & 8.2 & $7-15$ \\
\hline $0.075 \mathrm{~mm} \mathrm{\# 200}$ & 0.45 & 3.3 & $0-8$ \\
\hline Asphalt content $\%$ & \multicolumn{2}{|c|}{$3.88 \%$} & $3.5-7.0$ \\
\hline
\end{tabular}

TABLE 3. The physical properties of the aggregate.

\begin{tabular}{|c|c|c|c|c|c|c|}
\hline \multirow{2}{*}{ Property } & \multirow{2}{*}{$\begin{array}{c}\text { AASHTO } \\
\text { Test } \\
\text { Method }\end{array}$} & \multicolumn{2}{|c|}{ Coarse Aggregate } & \multirow{2}{*}{$\begin{array}{c}\text { Fine } \\
\text { Aggregate }\end{array}$} & \multirow{2}{*}{$\begin{array}{l}\text { Mineral } \\
\text { Filler }\end{array}$} & \multirow{2}{*}{$\begin{array}{c}\text { AASHTO } \\
\text { Specification }\end{array}$} \\
\hline & & Agg. (1) & Agg. (2) & & & \\
\hline $\begin{array}{l}\text { Los Angeles Abrasion (Loss } \\
\text { wt. \%) }\end{array}$ & Т $96-83$ & 19.2 & 18.4 & ----- & ------ & Max. $40 \%$ \\
\hline Bulk specific gravity $\mathrm{G}_{\mathrm{sb}}$ & T $85-85$ & 2.50 & 2.478 & 2.65 & 2.701 & ------ \\
\hline Apparent specific gravity & T $85-85$ & 2.62 & 2.615 & ------ & ------ & ------ \\
\hline Specific gravity SSD & T $85-85$ & 2.684 & 2.679 & ----- & ------ & ------ \\
\hline Water absorption (wt. \%) & T $85-85$ & 1.16 & 1.17 & ------ & ----- & Max. $5 \%$ \\
\hline Stripping & T $85-85$ & $>95 \%$ & $>95 \%$ & ------ & ------ & $>95 \%$ \\
\hline
\end{tabular}

Egypt.J.Chem. Vol. 61, No.2 (2018) 


\section{Marshall mix design}

Marshall mix design method was originally developed by Bruce Marshall of the Mississippi Highway Department in 1939. The main idea of the Marshall Mix Design method involves the selection of the asphalt binder content with a suitable density which satisfies minimum stability and range of flow values. In this test, samples of aggregate and bitumen mixed and compacted in both sides no. of blows and it is classified according to the temperature used as HMA, WMA and CIR, for each compacted sample of the asphalt paving mix, the stability and flow are measured while the unit weight and air voids are calculated to define the optimum asphalt content. Marshall mix design references are ASTM D-6927 - 15 \& AASHTO T-245 - 2012

Preparation of asphalt paving mix design samples

The asphalt paving mixes were prepared using Marshall test method (ASTM D-6927 - 15 \& AASHTO T-245 - 2012)[21, 22] including three types of design; HMA, WMA and CIR. For each compacted sample of the asphalt paving mix, the stability and flow are measured while the unit weight and air voids are calculated to define the optimum asphalt content. In this step; hot mix asphalt using of virgin and modified asphalt samples were prepared using the Marshall test procedure. All the mixes were designed according to the Egyptian Specification limits for dense graded hot mix asphalt (Dense -Graded 4D) for binder course knowing that;

Mix (1): "control mix" it consists of virgin asphalt $\mathrm{AC}$ added to RAP by HMA.

Mix (2): it consists of PMA, using 4 wt.\%StBuAcopolymer added to RAP by HMA.

Mix (3): it consists of PMA, using 4 wt.\%StBuAcopolymer added to RAP by WMA.

Mix (4): it consists of PMA, using 4 wt.\%StBuAcopolymer added to RAP by CIR.

\section{Result and Discussion}

Characterization of nanoemulsion terpolymer Fourier transform infrared (FTIR)

FTIR spectrum shown in Fig. 1 and Table 4 illustrate the function groups :

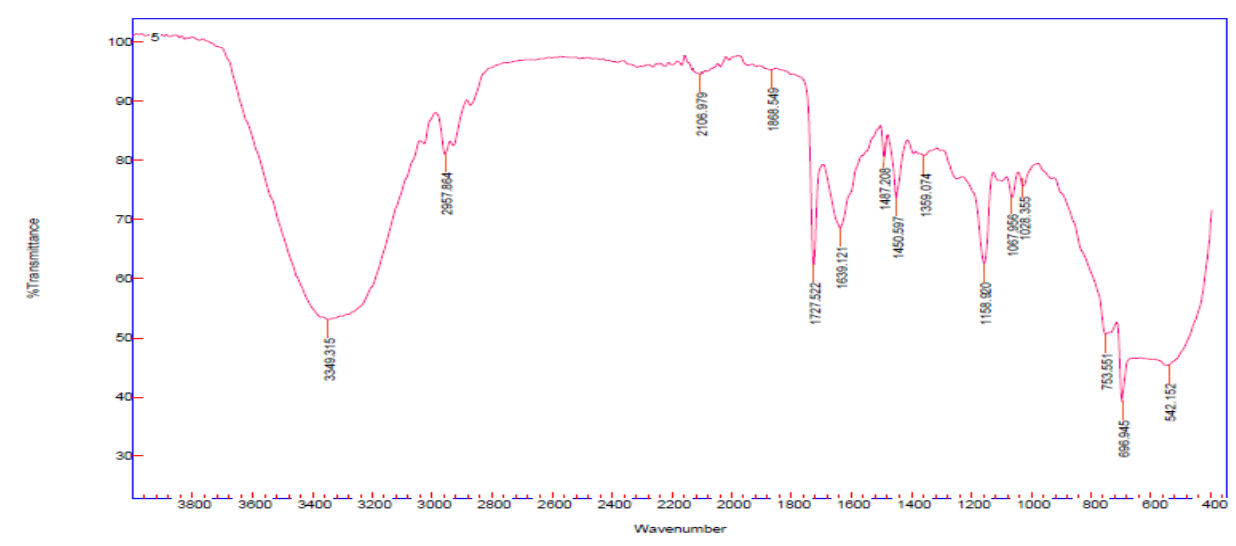

Fig. 1. FTIR spectra of the prepared Styrene - butyl acrylate copolymer.

TABLE 4. FTIR spectra of the prepared Styrene - butyl acrylate copolymer.

\begin{tabular}{|c|c|}
\hline Wave number $\mathrm{Cm}^{-1}$ & Assign \\
\hline 3030 & C-H aromatic of Styrene ring \\
\hline 1732 & $\mathrm{C}=\mathbf{O}$ for acrylate ester \\
\hline \multirow[t]{2}{*}{2900} & C-H Aliphatic of butyl acrylate \\
\hline & $\begin{array}{l}\text { The presence of functional groups bands together with absence of vinyl group } \\
\text { may be good evidence on the copolymer formation }\end{array}$ \\
\hline
\end{tabular}

Molecular weight (Mwt)

M.wt results for St-BuA nanoemulsion copolymer shown in Fig. 2 Illustrate that, the relative time (RT) is $1.69-4.43$, where M.wt average is 806 and the mass over a charge number of ions is $50.00-804.57$. 

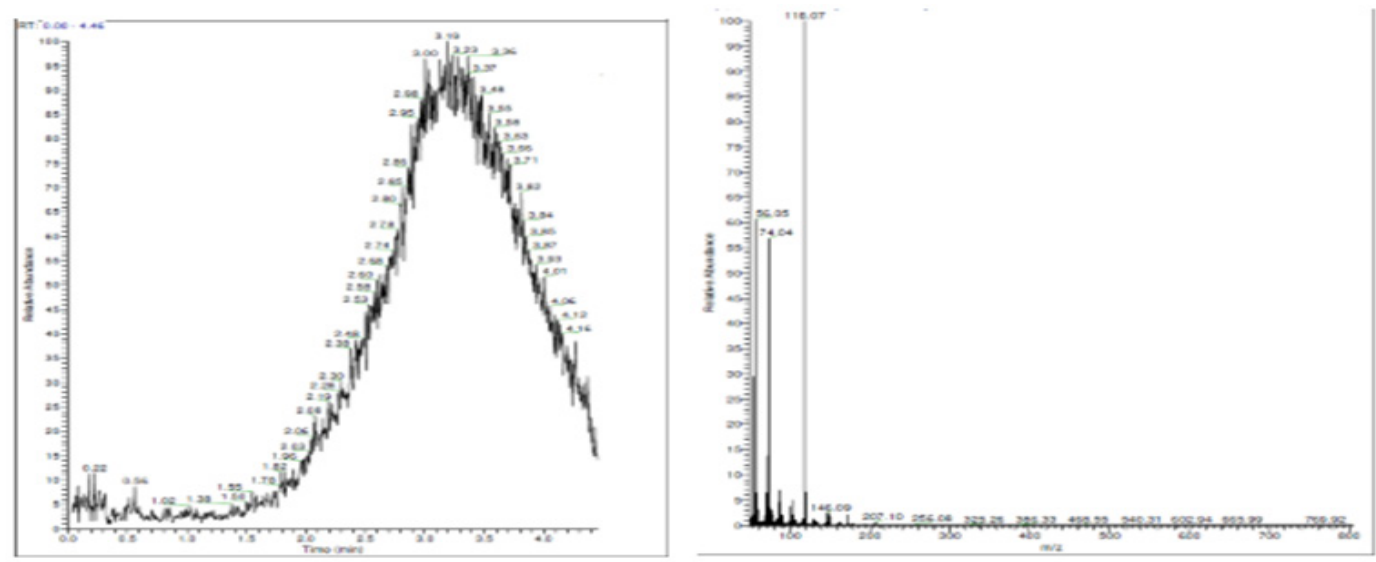

Fig. 2. Molecular weight of the prepared Styrene - butyl acrylate copolymer.

Thermo gravimetric analysis (TGA)

The TGA shown in Fig. 3 showed that, the decomposition temperature of the prepared nanoemulsion copolymer is between $370-420^{\circ} \mathrm{C}$, the weight loss 15,50 and $90 \%$ at 298,338 and $460{ }^{\circ} \mathrm{C}$, respectively. The recorded weight residual at $600{ }^{\circ} \mathrm{C}$ was $5.4 \%$.

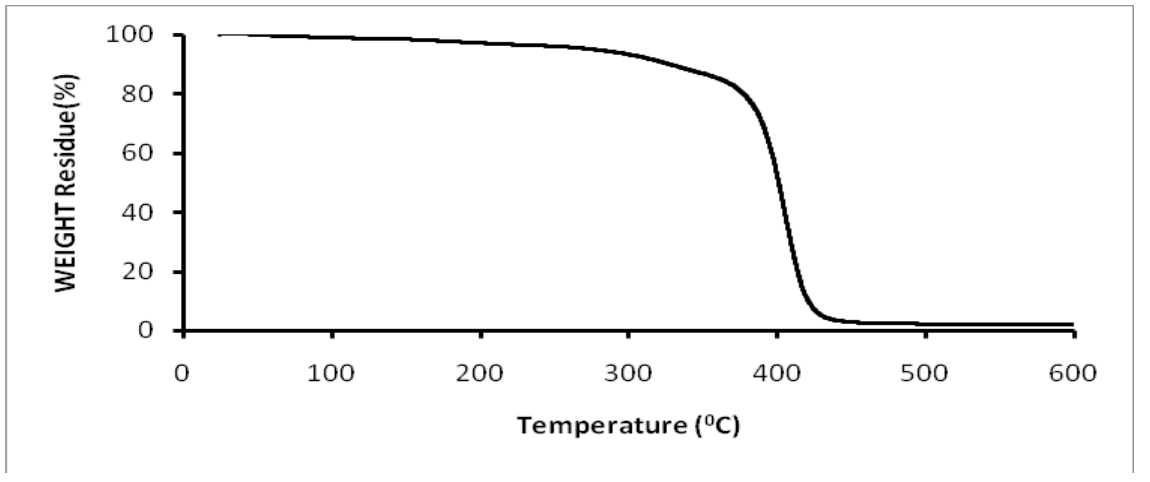

Fig. 3. TGA of the prepared Styrene - butyl acrylate copolymer.

Transmission electron microscopy (TEM)

Figure 4 shows the TEM of the St-BuA copolymer. It is clear from the figure that the diameters of the observed particles of the polymer range between $1.0 \mu \mathrm{m}$ and $100 \mathrm{~nm}$. The implication here is that the progressive emulsion of the polymer improved the structure and robustness of the polymer. All particles are spherical and consist of a core from St-BuA. It is clear from the image that the particles are spherical in shape without any deformation with narrow distribution.
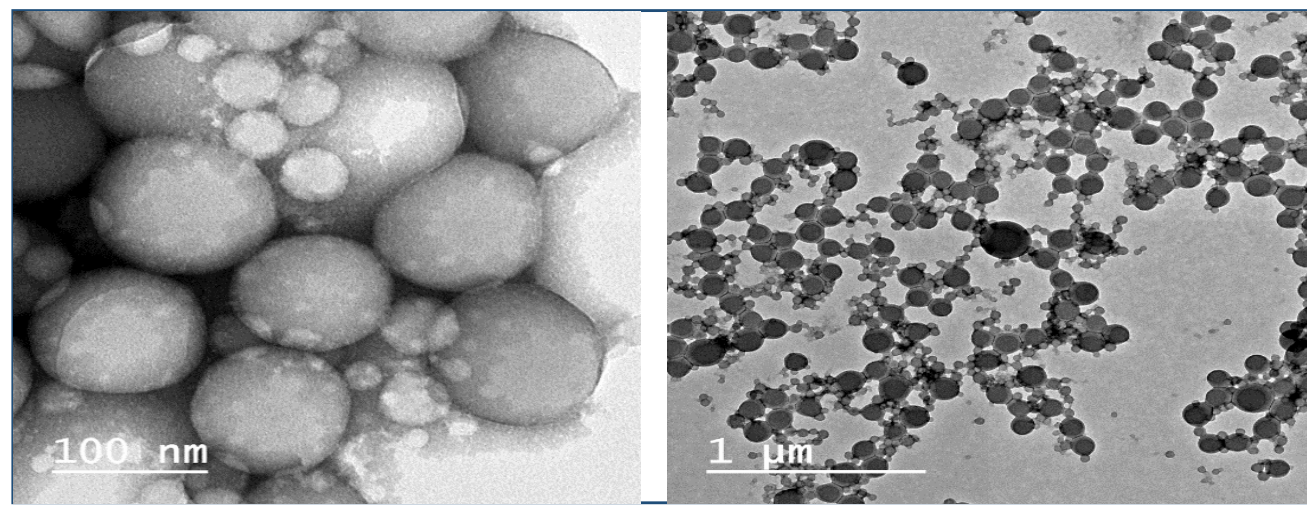

Fig. 4. TEM for Styrene - butyl acrylate copolymer.

Egypt.J.Chem. Vol. 61, No.2 (2018) 


\section{Modification of asphalt}

Table 5 illustrates the physical characteristics of the virgin asphalt and the modified asphalt with 2,4 and 6 wt.\% St-BuA copolymer. The obtained results showed that, the modification of asphalt with St-BuA copolymer produces a binder more hardener than the virgin sample, as it has lower penetration and higher kinematic viscosity and softening point. This may be attributed to this type of polymer which produces a fine dispersion of the polymer in molten (solvating) phase with no disturbance of the asphalt structure, as it is a thermoplastic and a flexible polyolefin which does not contain any double bonds. Generally, the polymer creates a network to the asphalt molecule.

TABLE 5. The physical characteristics of the used asphalt.

\begin{tabular}{|c|c|c|c|c|c|}
\hline \multirow{2}{*}{ Physical characteristics } & \multirow{2}{*}{ Virgin AC } & \multicolumn{3}{|c|}{ Copolymer wt. $\%$} & \multirow{2}{*}{ ESP* } \\
\hline & & 2 & 4 & 6 & \\
\hline Penetration (at $\left.25^{\circ} \mathrm{C}, 100 \mathrm{~g}, 5 \mathrm{~s}\right) 0.1 \mathrm{~mm}$ & 63 & 63 & 65 & 68 & $60 / 70$ \\
\hline Softening point (ring $\&$ ball) ${ }^{\circ} \mathrm{C}$ & 46.5 & 49 & 51 & 54 & $45 / 55$ \\
\hline Specific gravity (at $25 / 25$ ) ${ }^{\circ} \mathrm{C}$ using a pycnometer & 1.02 & 1.044 & 1.092 & 1.111 & Not specified \\
\hline Kinematic viscosity (at $135^{\circ} \mathrm{C}$ ) cSt & 380 & 520 & 610 & 885 & $>320$ \\
\hline
\end{tabular}

(*)Egyptian Standard Specification limits.

The obtained data also showed that, the penetration, softening point, kinematic viscosity of the modified asphalt improved by incorporation of different wt.\% of the prepared emulsion copolymer, as the obtained results are within the specified criteria, where the specific gravity does not have specific requirements.

\section{Evaluation of characteristics of prepared samples}

In accordance with the Egyptian standard, the optimum asphalt content of the AC mixture was determined using the Marshall mix design methodology using different mix design types as below;

St-BuA copolymer prepared and mixed with virgin asphalt in three different percentages using terpolymer 2, 4 and 6 wt.\% content, according to test results the best results obtained to apply using Marshall design was 4\%. The application of Marshall design included three types which were prepared by hot mix asphalt, WMA and cold in place recycled. However, all mixtures met the Egyptian Specification for Road. Air void content, stability and other characteristics are illustrated in
Table 6 and Fig. $5-12$, and comparing to the control mix (1) the following results are detected,(a) the optimum asphalt content increased compared to control mix ( $0.217 \%$ for HMA), and $(0.35 \%$ for WMA) and decreased ( $0.033 \%$ for CIR); (b) the stability of the RAP without any modification was $325 \mathrm{Kg}$, where for control mix was $1050 \mathrm{Kg}$, on the other hand it increased from $1050 \mathrm{Kg}$ to 1550 $\mathrm{Kg}$ for HMA, where it is increasedto $1350 \mathrm{Kg}$ for WMA and decreased to $800 \mathrm{Kg}$ for CIR; (c) Marshall stiffness of the prepared mixes increased from 86.06 for control mix to 121.09 and 103.05 $\mathrm{Kg} / \mathrm{Inch}$ for HMA and WMA respectively, this is due to the increase of stability and decrease in flow values where Marshall stiffness is not required for CIR; (d) The air voids decreased from $4.8 \%$ to $4.5 \%$ for HMA and increased to 5.5 for WMA and 9.8 for CIR; (e) The voids in mineral aggregates increased from $15.25 \%$ to $15.6 \%$ for HMA and to $16.65 \%, 19.9 \%$ for WMA and CIR respectively, and (f) voids filled with asphalt increased from $68.52 \%$ to $70.06 \%$ for HMA and decreased for WMA to $67.0 \%$

TABLE 6. Marshall Characteristics of the prepared asphalt Mixes.

\begin{tabular}{|c|c|c|c|c|c|c|}
\hline \multirow[b]{2}{*}{ Characteristic } & \multicolumn{5}{|c|}{ Mix No. } & \multirow{2}{*}{$\begin{array}{c}\text { Standard } \\
\text { limits }\end{array}$} \\
\hline & $\mathbf{R A P}$ & $\begin{array}{l}\text { Control mix } \\
\text { (1) }\end{array}$ & $\begin{array}{l}\text { HMA } \\
(2) \\
\end{array}$ & $\begin{array}{l}\text { WMA } \\
\text { (3) } \\
\end{array}$ & $\begin{array}{l}\text { CIR } \\
(4) \\
\end{array}$ & \\
\hline Optimum Asphalt Content (\% wt.) & 3.88 & 5.503 & 5.72 & 5.853 & 5.536 & $3.5-7.0$ \\
\hline Stability of the mix (Kg.) & 325 & 1050 & 1550 & 1350 & 800 & Min. $700 \mathrm{Kg}$ \\
\hline Unit weight of the mix $\left(\mathrm{Kg} / \mathrm{m}^{3}\right)$ & 1.836 & 2.308 & 2.300 & 2.270 & 2.180 & NS ${ }^{(*)}$ \\
\hline Flow of the mix $(0.01 \mathrm{inch})$ & 8.0 & 12.2 & 12.8 & 13.1 & 12.0 & $8-16$ \\
\hline Air voids in CIR mix ( \% ) & & & & & 9.8 & $9-14$ \\
\hline Air voids in solid materials ( $\%$ ) & 17.8 & 15.25 & 15.6 & 16.65 & 19.9 & Min. \\
\hline Voids Filled with Asphalt ( $\%$ ) VFA & 57.9 & 68.9 & 70.06 & 67.0 & $\mathrm{NR}^{(* *)}$ & $\begin{array}{l}65- \\
75\end{array}$ \\
\hline Marshall stiffness Kg/in & 40.6 & 86.06 & 121.09 & 103.05 & $\mathrm{NR}^{(* *)}$ & $\mathrm{NS}^{(*)}$ \\
\hline
\end{tabular}




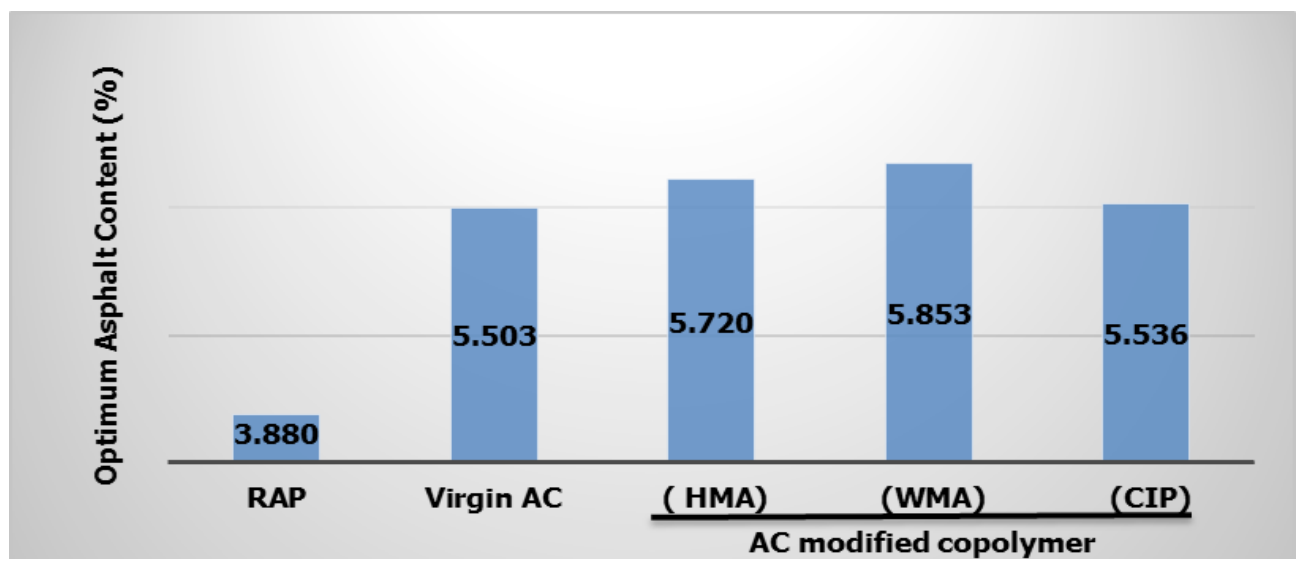

Fig. 5. Optimum Asphalt Content for all mixes.

The optimum asphalt content was increased for mixes HMA and WMA from 5.503 to 5.72 and 5.853\%, where decreased for CIR mix to $5.536 \%$.
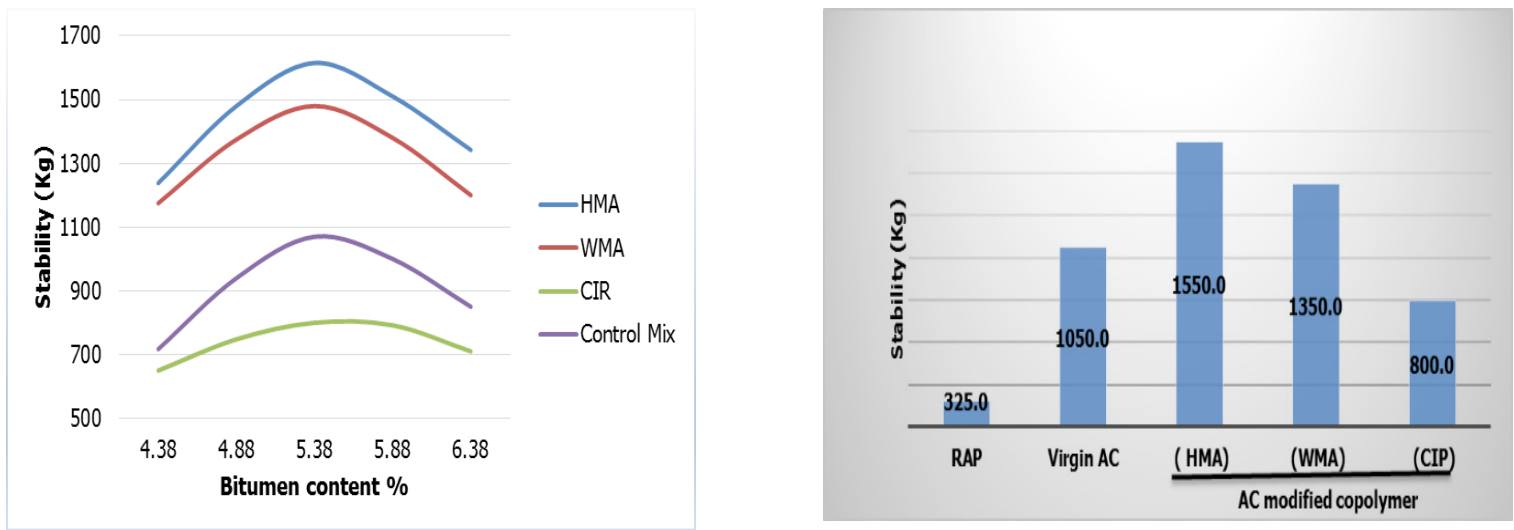

Fig. 6. Stability results for all mixes.

The stability increased for HMA and WMA mixes to be 1550 and $1350 \mathrm{Kg}$ respectively, then decreased for CIR mix to $800 \mathrm{Kg}$ compared to $1050 \mathrm{Kg}$ for the control mix using virgin asphalt and 325 for RAP without any modification.
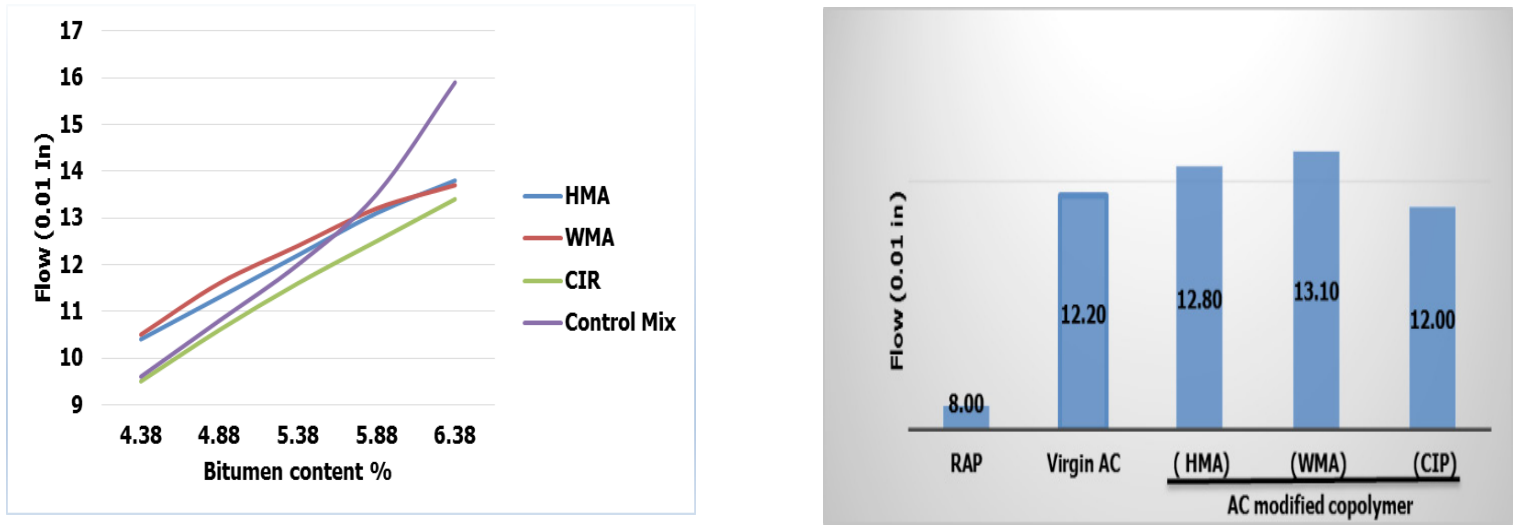

Fig. 7. Flow results for all mixes.

Flow results for all mixes ranged between 12.0 to $13.1(0.01)$ inch. 

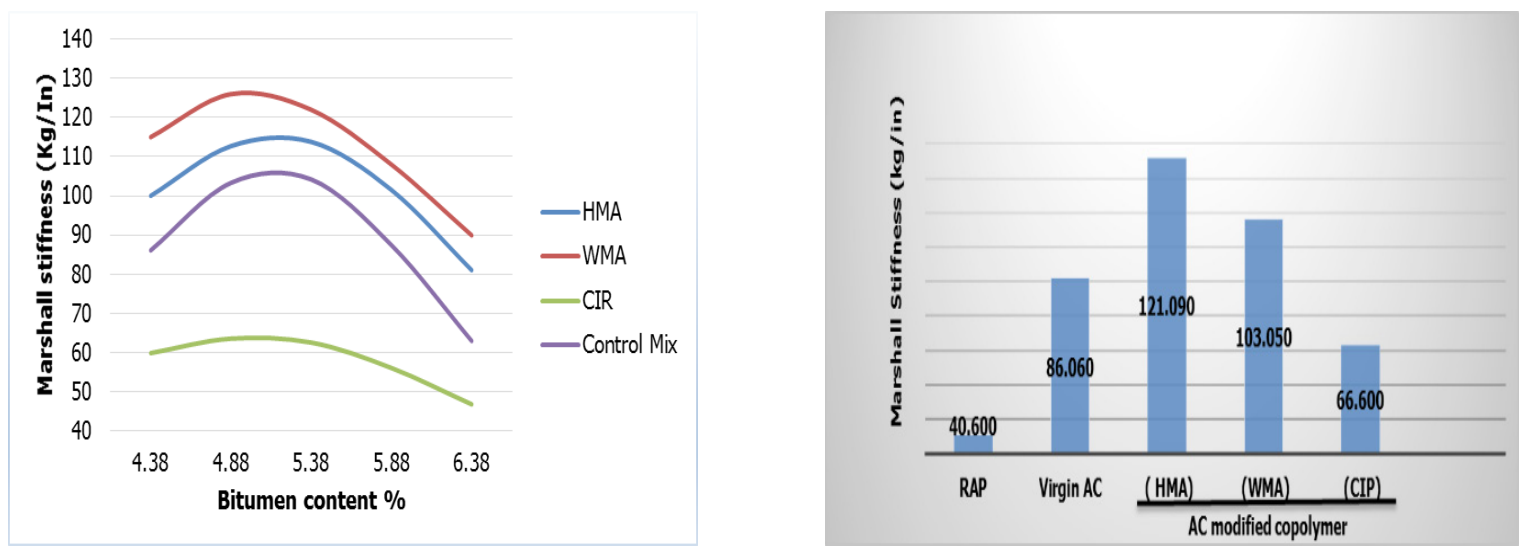

Fig. 8. Marshall stiffness results for all mixes.

Marshall stiffness of the prepared mixes increased from 86.06 for control mix to 121.09, 103.05 for HMA \& WMA mixes respectively.
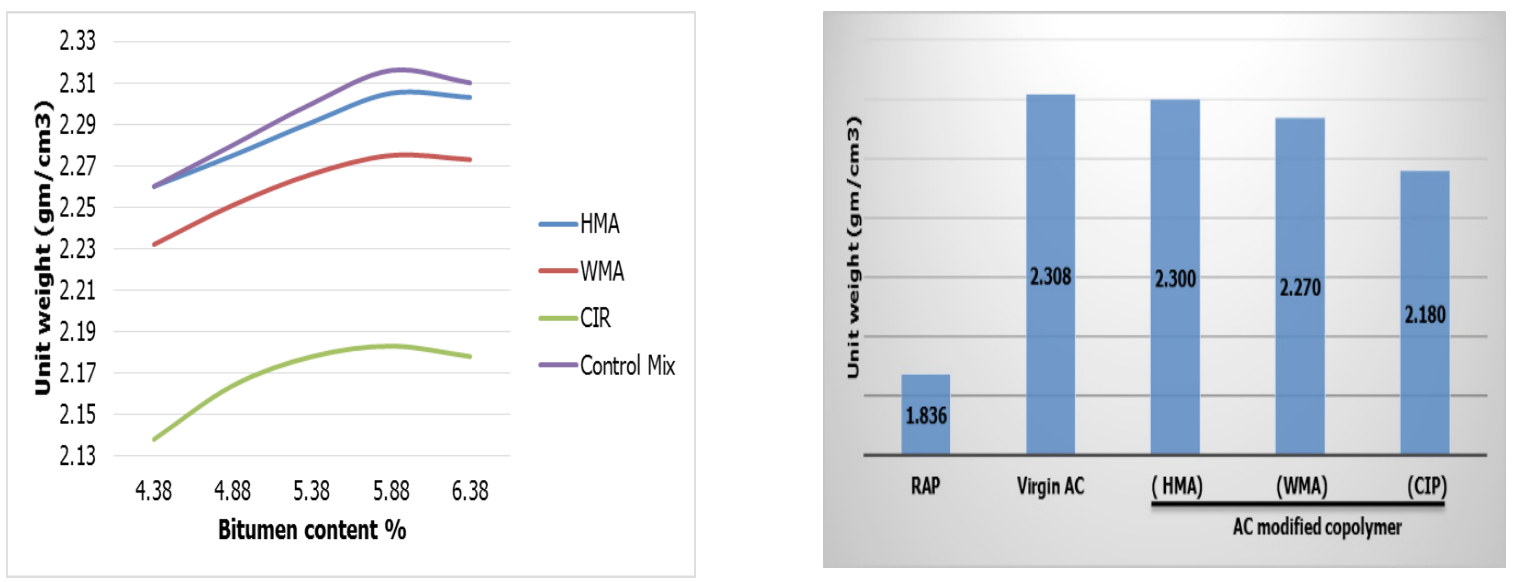

Fig. 9. Unit weight results for all mixes.

Unit weight for all mixes ranged between 2.18 to $2.308 \mathrm{gm} / \mathrm{cm} 3$
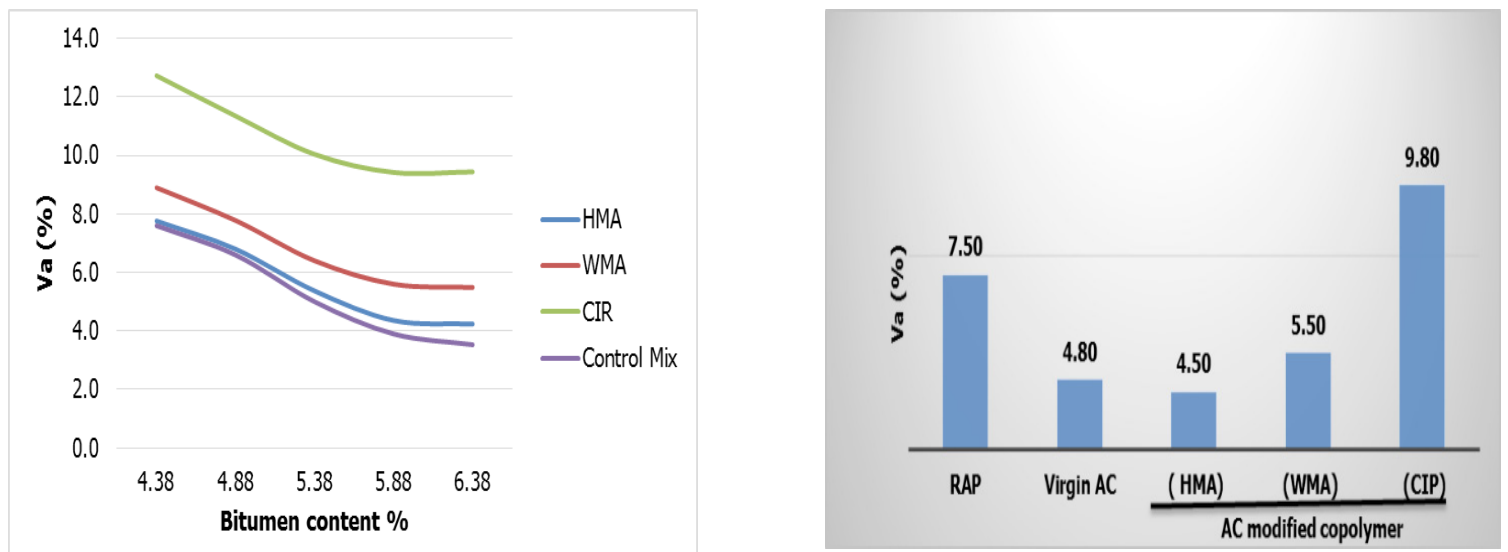

Fig. 10. Air voids results for all mixes.

The percent of air voids in the mix for HMA mix decreased from 4.8 to $4.5 \%$ and increased for WMA \& CIR mixes from 4.8 to 5.5 and $9.8 \%$ respectively. 

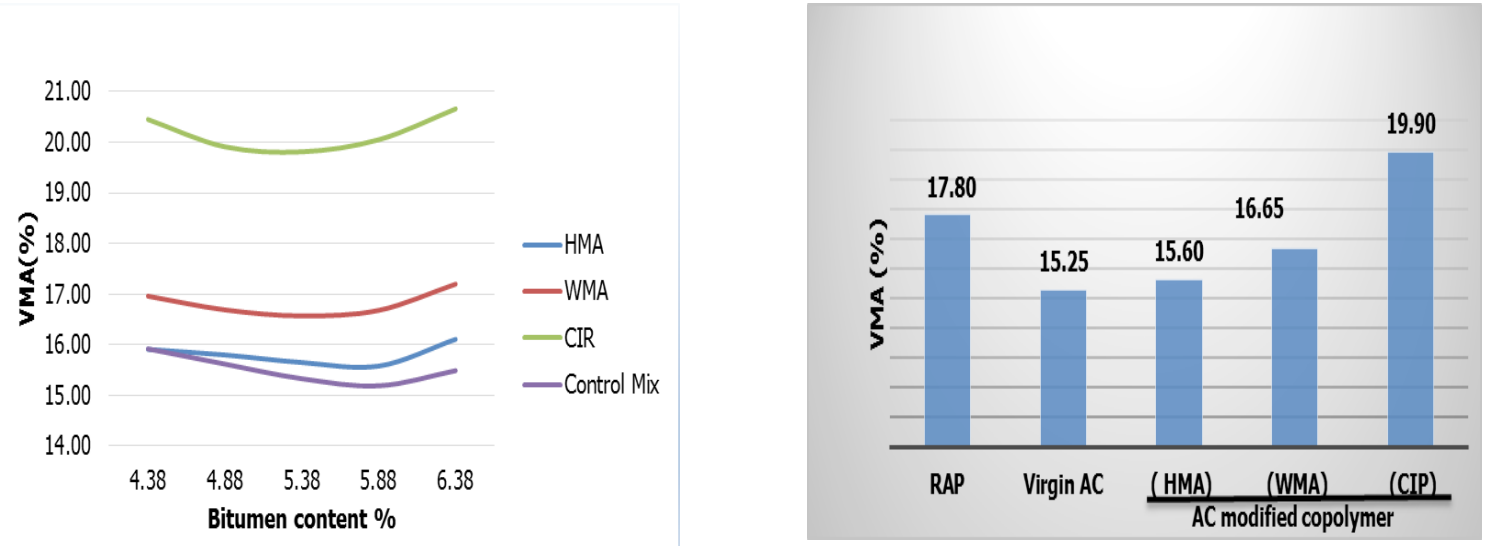

Fig. 11. Voids in mineral aggregate results for all mixes.

The percent air voids in mineral materials increased for HMA mix from 15.25 to 15.6 and to 16.65 and 19.9 for WMA \& CIR mixes respectively.
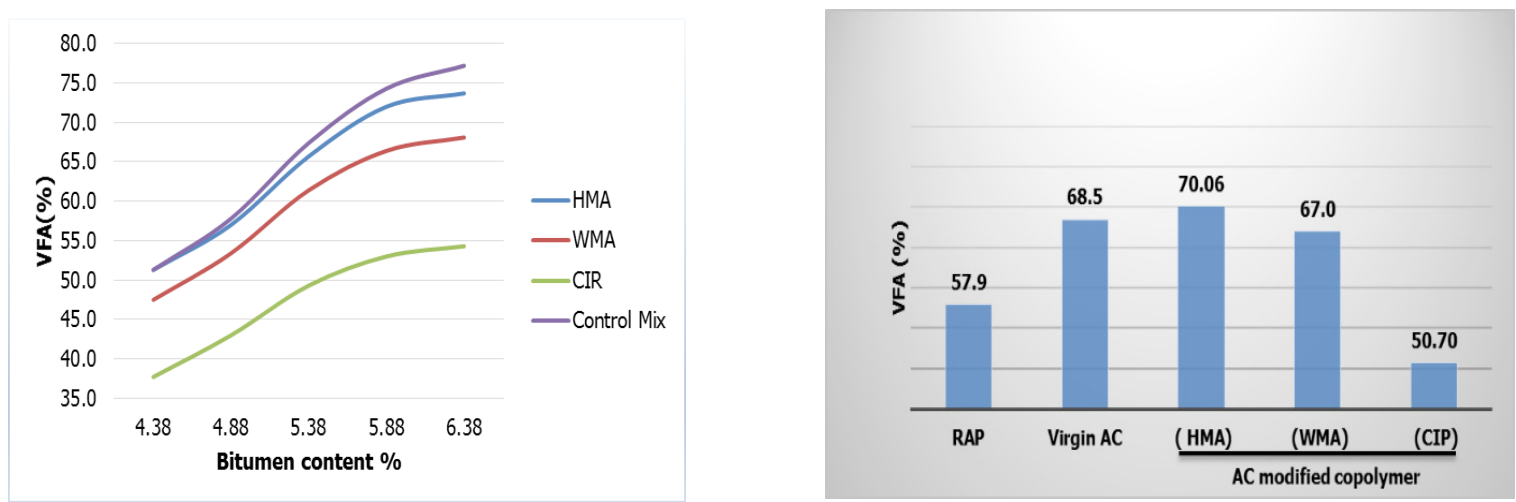

Fig. 12. Voids filled with asphalt results for all mixes.

Voids filled with asphalt gives high result for HMA $70.06 \%$ where it was 67.0 for WMA comparing to control mix it was $68.5 \%$.

\section{Conclusion}

Asphalt modified by copolymer composition complies with the requirements of the Egyptian Standard Specification and has characteristics that are typical for using special polymer modifier: StBuA copolymer. This study focuses on evaluating the effects of polymer to modify RAP in order to improve the quality of paving and reduce the cost of asphalt using three different mix designs. In this study, the effect of using RAP mixtures was evaluated using Marshall mix design by three different types HMA, WMA, and CIR.

In this research, a content of 4 wt. $\%$ of StBuA copolymer was used as a polymer modified asphalt PMA and applying Marshall mix design as HMA, WMA and CIP. The research results show a change in stability, the milled asphalt mixture that included $3.88 \%$ asphalt, the optimum asphalt content was ranging between $1.65-1.97 \%$, which designate the polymer modified by 0.066 $-0.078 \%$. All mix types of HMA, WMA and CIP have achieved the required specification for stability and all other requirements and this will lead to the production of an asphalt mix in a higher performance and longer service life accordingly.

The research achieved using nanoemulsion copolymer as RAP modified with required quality according to required specification

The application of the Marshall design for control mix and the modified mixes showed that:

- The optimum asphalt content was slightly increased for mix no. (2). the content was increased from 5.503 to $5.720 \%$ wt., where, it increased for mix no. (3) from 5.503 to $5.853 \%$ wt. Finally in mix no. (4), it observed the optimum asphalt content decreased from 


\subsection{3 to $5.536 \%$ wt.}

- The stability increased for mixes no. (2) and (3) and then decreased for mix no. (4), the value increased from $1050 \mathrm{Kg}$ to 1550 and $1350 \mathrm{Kg}$. and decreased to $800 \mathrm{Kg}$.

- $\quad$ The percent of air voids in mix for mixes no. (2) decreased from 4.8 to 4.5 and for mixes no. (3) \& (4) the air voids increased to 5.5 and 9.8

- The percent air voids in solid materials increased for mix no. (2) from 15.25 to 15.6 and then increased for mixes No. (3) and (4) to 16.65 and 19.9 respectively.

- Marshall Stiffness of the prepared mixes increased from 86.06 for control mix to 121.09 and 103.05 for HMA and WMA respectively.

- From the above results it is obvious that the addition of St-BuA nanoemulsion copolymer up to content of $4 \%$ enhances the stability of the asphalt mix.

- $4 \%$ addition of St-BuA nanoemulsion copolymer produces HMA has good Marshall stability as well as it gives preferable general characteristics of the modified asphalt rather than WMA and CIP.

- Polymer modified asphalt amount ranged between $0.06 \%$ for CIR, $0.074 \%$ for HMA, and $0.078 \%$ for WMA.

\section{Acknowledgment}

The authors would like to thank Prof Long Lin, Department of Colour Science, University of Leeds, Leeds LS2 9JT, UK for his help and support in reviewing the paper

\section{References}

1- Hansen KR, Copeland A., Annual asphalt pavement industry survey on recycled materials and warm-mix asphalt usage: 2009-2012. No. IS-138. National Asphalt Pavement Association, Lanham, Maryland (2013).

2- Bulatović VO, Rek V, Marković KJ., Effect of polymer modifiers on the properties of asphalt. $J$ Elastom Plast 46, 448-469 (2014)

3- Bonaquist R. Laboratory Evaluation of Hot Mix Asphalt (HMA) Mixtures Containing Recycled or Waste Product Materials Using Performance Testing, Publication FHWA-PA-2005-006+98-32
(19), Pennsylvania Department of Transportation, Office of Planning and Research (2005).

4- McDaniel R., Shah A., Huber G., Gallivan V. Investigation of Properties of Plant-Produced RAP Mixtures. Transportation Research Record: Journal of the Transportation Research Board, No. 1998, Transportation Research Board of the National Academies, Washington, D.C., pp. 103111 (2007).

5- Glover, C., Epps Martin A., Chowdhury A., Han R., Prapiatrakul N., Jin X., and Lawrence J. Evaluation of Binder Aging and Its Influence in Aging of Hot Mix Asphalt Concrete: Literature Review and Experimental Design, Report FHWA/ TX-08/0-6009-1, Texas Transportation Institute, College Station, TX. (2009).

6- Johnson, E, Johnson G, Dai S, Linell D, McGraw $\mathrm{J}$, and Watson $\mathrm{M}$ Incorporation of Recycled Asphalt Shingles in Hot Mixed Asphalt Pavement Mixtures, Minnesota Department of Transportation, Maplewood, MN. (2010).

7- Giani MI, Dotelli G, Brandini N, Zampori L Comparative life cycle assessment of asphalt pavements using reclaimed asphalt, warm mix technology and cold in-place recycling. Resour Conserv Recycl 104, 224-238 (2015).

8- Bowers BF, Huang B, Shu X, Miller BC Investigation of reclaimed asphalt pavement blending efficiency through GPC and FTIR. Constr Build Mater 50, 517-523 (2014).

9- Mogawer W.S., Austerman A.J., Roussel M. Performance Characteristics of Asphalt Rubber Mixtures Containing RAP and Warm Mix Asphalt Technology. Proceedings of the 2nd International Warm-Mix Conference, St. Louis, MO (2011).

10- Zhang YF, Zhang R, Yang CL, Xu J, Zheng J, Lu MG, Stable acrylate/triethoxyvinylsilane (VTES) core-shell emulsion with low surface tension made by modified micro-emulsion polymerization: effect of different mass ratio of MMA/BA in the core and shell. Colloids Surf A Physicochem Eng Asp 436, 549-556 (2013)

11- Gudimettla J., Cooley L., Brown E. Workability of Hot Mix Asphalt. Report \#03- 03, National Center for Asphalt Technology (NCAT), Auburn, AL. (2003).

12- Abd El-Wahab H., Saleh A. M. M., Wassel M. A., Elkady G., Khalaf N. S., and Ahmed S. Preparation and evaluation of a new anti-corrosive

Egypt.J.Chem. Vol. 61, No.2 (2018) 
coating based on asphalt cement blended with polyesteramide resin for steel protection, 1363 1368 (2013).

13- Mangiafico S, Di Benedetto H, Sauzéat C, Olard F, Pouget S, Planque L New method to obtain viscoelastic properties of asphalt blends from pure and reclaimed asphalt pavement binder constituents. Road Mater Pavement Des 15, 312329 (2014)

14- Brovelli C, Crispino M, Pais, J, and Pereira, P. Using polymers to improve the rutting resistance of asphalt concrete. Construction and Building Materials, 77, 117-123 (2015).

15- Hashemi-Nasab R, Mirabedini SM Effect of silica nanoparticles surface treatment on in situ polymerization of styrene-butyl acrylate latex. Prog Org Coat 76, 1016-1023 (2013).

16- Khezri K, Haddadi-Asl V, Roghani-Mamaqani $\mathrm{H}$, Salami-Kalajahi M ,Synthesis of well-defined clay encapsulated poly (styrene-co-butyl acrylate) nanocomposite latexes via reverse atom transfer radical polymerization in miniemulsion. $J$ Polym Eng 32, 111-119 (2012).

17- Tapsoba N, Sauzéat C, Di Benedetto H, Baaj H, Ech $\mathrm{M}$ Behaviour of asphalt mixtures containing reclaimed asphalt pavement and asphalt shingle. Road Mater Pavement Des 15, 330-347 (2014).
18- Hoppe EJ, Lane DS, Fitch GM, Shetty S., Feasibility of RAP use as road base and subbase material. Report No. VCTIR 15-R6. Virginia Center for Transportation Innovation and Research, Virginia (2015).

19- Kriz P, Grant DL, Veloza BA, Gale MJ, Blahey AG, Brownie JH, Shirts RD, Maccarrone S., Blending and diffusion of reclaimed asphalt pavement and virgin asphalt binders. Road Mater Pavement Des 15, 78-112 (2014).

20- Abdel-Rahman M., Ahmed I., Mohamed B., Hamada A., and Alaa T., Preparation and characterization of some nanoemulsion polymers for paper coating applications, 52 - 53 (2017).

21- American Society for Testing and Materials (ASTM) Road and paving materials: traveled surface characteristics. In: Annual Book of American Society for Testing and Materials, Vol. 4.03, D 6927-15. ASTM, U.S.A. (2005).

22- American Association of State Highway and Transportation Officials (AASHTO) Part 2 Tests, T-245. In: Standard specifications for transportation materials and methods of sampling and testing. AASHTO, Washington, DC. (2012)

(Received 19/2/2018; accepted 12/4/2018)

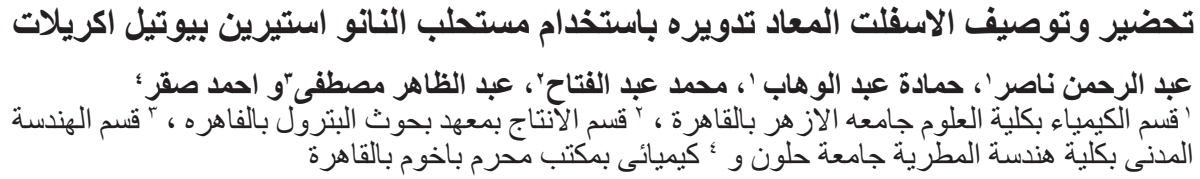

الاسفلت المعاد تدويره ذات اهمية كبرى لأنه يوفر ويقلل تكلفة البناء ، مع زيادة الاستدامة البيئية, الهدف الرئيسى الهي

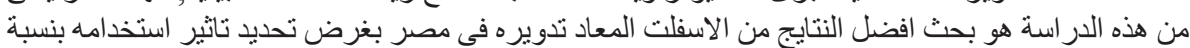

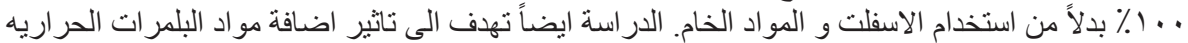

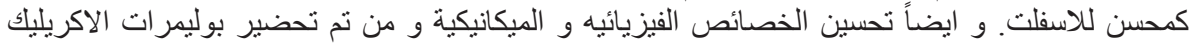

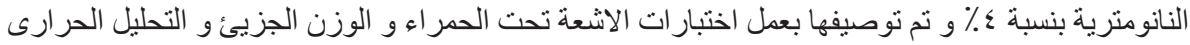

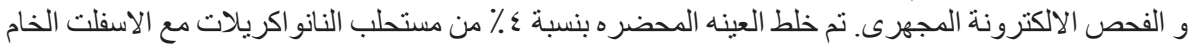

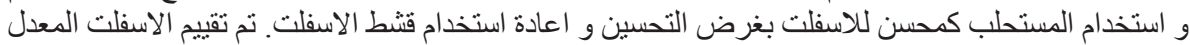

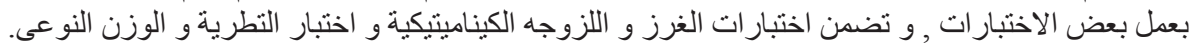

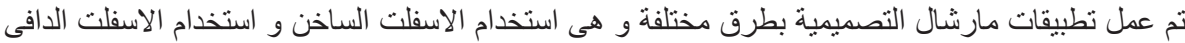

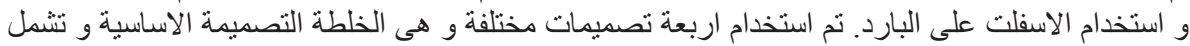
الاسفلت الخام بطريقة الاضافة على الساخن فى حين الثلاث تصميمات الاخرى عبارة عن عن استخدام الاسفلت المعدل بمو اد المستحلبات بطريقة الاصافه على الساخن و ولى على الدافى و على الصى البارد.

ومما سبق ومن خلال التجارب المعملية والنتائج التى تم الحصول عليها تم اتوصل الى ان استخدام الاسفلت

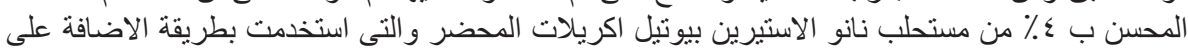

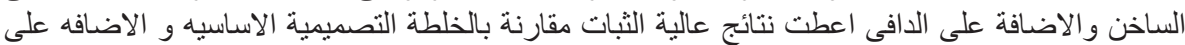
البارد 